\title{
Dr Ananda W Atukorala - Paediatric Radiologist
}

MBBS (Cey), DMRD (RCP\&S), FRCR (UK), FSLCPaed

Sri Lanka Journal of Child Health 2007; 36: 151

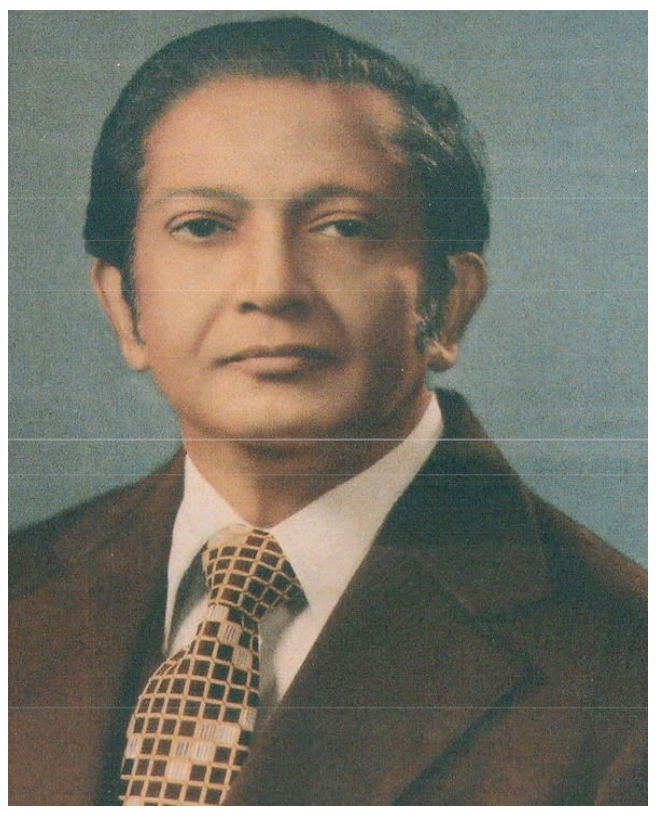

Dr Ananda W Atukorala who passed away recently at the age of 82 years was a well-known paediatric radiologist. After studying at Trinity College, Kandy he entered the Colombo Medical Faculty and graduated in 1951. Thereafter he worked as a medical officer at Lady Ridgeway Hospital (LRH) and benefited by coming under the wing of Professor C C de Silva, who guided him to a career in radiology.

His training in radiology commenced at the General Hospital Colombo and he left for training overseas in September 1954. He trained at St. Mary's Hospital, Paddington, London, and later at the Hospital for Sick Children, Great Ormond Street, London. At the latter hospital he came under the influence of Professor John Sutcliffe with whom he established a life-long friendship.

Dr. Atukorala returned to Ceylon in 1957 and served as a radiologist in Kandy, Ratnapura, Kurunegala and in Kandy again before assuming duties as consultant paediatric radiologist at LRH in 1971. At LRH he spent a very enjoyable and productive time. His office was the meeting place for most of us who used to visit him to discuss diagnostic problems, which extended to entertaining banter and relaxation thereafter. His friendliness and expertise helped to establish close bonds with fellow consultants. He used to organize the clinical meetings on Monday afternoons in the 70 's, which were very well attended by doctors not working at LRH as well. He was the President of the
Association of Sri Lanka Radiologists as well as the President of the Sri Lanka Paediatric Association from 1978/79. He retired from the Ministry of Health in 1980 and worked as a paediatric radiologist at the Bradford Royal Infirmary, UK from 1980 to $1991 . \mathrm{He}$ excelled in culinary skills and our family experienced his expertise in the 80's. In 1985 he obtained membership of the Radiological Society of North America and was elected Fellow of the Royal College of Radiologists (UK) in 1987.

After retiring from Bradford in 1991, his thirst for new frontiers made him accept an assignment at the Ann Arbor Hospital, University of Michigan, USA, in the years 1991 to 1992.

After returning to Sri Lanka, he made available the new radiological investigating techniques and skills by working in the private sector, where he was much in demand and readily accessible.

In 1993, he delivered the Professor C C de Silva memorial oration titled "Red goggles to PET". In 1997 he was elected Fellow of the Sri Lanka College of Paediatricians. He was also elected President of the Sri Lanka College of Radiologists from 1995/96.

Dr. Atukorala was a genial, charitable person who exuded good fellowship with malice towards none. He lived a full life, enjoying a good quality of life and rendering a selfless service to his wide range of patients and friends until the very last. His colourful innings came to a sudden but peaceful end on the $2^{\text {nd }}$ of July 2007. He leaves behind his beloved wife Vivian, their daughter, two sons and their families to whom we extend our deepest sympathies.

May he attain the supreme bliss of Nirvana!

\section{Sanath P Lamabadusuriya}

